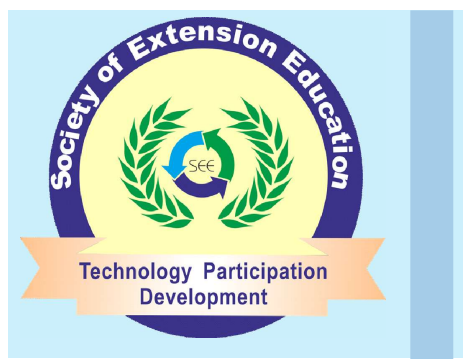

Research Article

\section{Indian Research Journal of Extension Education}

ISSN: 0972-2181 (Print), 0976-1071 (Online)

NAAS Rating : 5.22

Journal homepage: seea.org.in

https://doi.org/10.54986/irjee/2022/jan

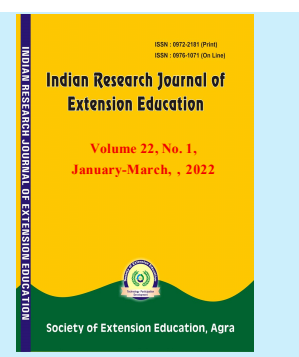

mar/103-109

\title{
Impact of Nutrition Education on Knowledge, Attitude and Practice (KAP) Levels of Selected Osteoporotic Subjects
}

\author{
B. Deshpande ${ }^{1}$, K. Hiremath ${ }^{2}$ and C. Divya ${ }^{3}$ \\ 1. Asso. Prof. (FSN), 3. P.G. Student, Department of Food Science \& Nutrition, UAS, Bangalore, \\ 2. Ayurveda Medical Practitioner \& P.G. Student, IGNOU, New Delhi \\ Corresponding author e-mail : banu.rtshastri@gmail.com
}

Paper Received on September 17, 2021, Accepted on Novembe 24, 2021 and Published Online on January 01,2022

\begin{abstract}
The study was undertaken to evaluate the impact of nutrition education on knowledge, attitude and practice levels of thirty volunteer osteoporotic subjects visiting orthopedic clinics of Davangere district of Karnataka state. Socioeconomic and nutritional status was assessed by standard procedures and nutrition education imparted on relevant aspects. A well-structured questionnaire of 15 statements with multiple answers was developed and used before and after one day counselling to determine knowledge, attitude and practice of the subjects. Hypertension was the common family medical history followed by diabetes mellitus and fractures. Absence of physical activities or exercises was evident. Rice was consumed on daily basis whereas ragi on weekly basis by maximum number of respondents. Grade I obesity was more prevalent among males (20\%) than female (5\%) whereas Grade II obesity was only observed in females (30\%). Assessment of knowledge gain after nutrition education revealed that Per centage gain in knowledge was more among male subjects (54.8\%) than female subjects (36.9\%) and that of attitude for both the subjects was at a range of 35.6 to $36.5 \%$. The per cent gain in practice was slightly higher among male subjects (19.3\%) compared to female subjects (15.0\%) The overall per centage gain of knowledge, attitude and practice for all subjects was 42.9 per cent, 37.4 per cent and 15.4 per cent respectively which was statistically significant $(p \leq 0.05)$ indicating the positive impact of nutrition education on KAP levels of the subjects.

Key words : Osteoporosis; Nutrition education; KAP; Nutritional status; BMD.
\end{abstract}

Osteoporosis is a major health disorder associated with an increased risk of fracture. Osteoporosis is characterized by low bone mass, micro architectural deterioration of bone tissue leading to enhanced bone fragility and consequently increasing the fracture risk among elderly people (Jameela Banu, 2013). There is an urgent requirement for the implementation of public health strategies to target prevention of poor skeletal health on a population-wide basis. As an exogenous factor, nutrition has a critical role to play in the optimization of bone health because nutrition is amenable to change and has relevant public health implications. Nutrition education can provide proper knowledge among the people regarding good health by optimum nutrition, preventive dietary measures for health ailments and also modify their attitude towards the better practice. In addition to achieving adequate nutrition associated with bone health through diet and fortified foods or supplements, proper nutrition counseling might assist in optimizing nutritional balance to support maintenance 
of bone mass. Hence, it was of interest to study the impact of nutrition education on knowledge, attitude and practice of selected orthopedic subjects suffering from symptomatic osteoporotic conditions, so that the knowledge imparted can lead to positive impact which may modify their status or improve their practices.

\section{METHODOLOGY}

A group of 10 males and 20 females aged between 30-60 years attending orthopedic health centers of Davangere district of Karnataka state were selected for the study. They were at risk of developing osteoporosis as per their symptomatic orthopedic ailments as suggested by the registered orthopedic surgeon. Willingness to participate in the study was the criteria for selection.

A pretested well-structured questionnaire was formulated and used to collect data on socio economic background such as family profile, age, education, marital status, monthly income, frequency of foods consumed, family medical history, physical activities/ exercise carried out etc. The body mass index (BMI) of the subjects was calculated and categorized accordingly (WHO, 1994) using the anthropometric measurements viz weight and height that were recorded using standard methods. Bone mineral density was measured by the instrument Ultrasound Bone Densitometer (SONOST-3000) with the help of a trained technician. TheT-scores of bone mineral density of Midshaft-Distal radius was measured sonographically [Speed of sound $(\mathrm{m} / \mathrm{sec})]$ in relation to the age of the person. The reports of T-scores were considered for classification of osteoporotic conditions as mentioned below.

\section{Classification of osteoporotic condition based on T-scores of BMD test}

\begin{tabular}{lll}
\hline T score up to & -1 & Normal \\
T score between: & -1.1 and -2.5 & Osteopenia \\
T score between: & $\leq-2.6$ & Osteoporosis \\
\hline
\end{tabular}

Nutrition education \& KAP test : Pretest of knowledge, attitude and practice was conducted before the nutrition education with a well-structured questionnaire of 15 statements with multiple answers to determine knowledge, attitude and practice of the subjects pertaining to bone health, nutrition, foods rich in calcium, vitamin D\& other functional nutrients and diet therapy for osteoporosis. Scores of 1, 0.75, 0.5 and 0.0 were allotted respectively to strongly agree, agree, disagree, and strongly disagree answers. The same questionnaire was used after counseling session. Nutrition education was conducted on relevant aspects such as causes and symptoms of osteoporosis, importance of nutrition for good health, preventive measures for osteoporosis, calcium and vitamin-D rich foods using individual and group counseling, demonstration of balanced diet and calcium rich foods, diet and calcium rich foods use of audio-visual on bone health and nutrition for effective dissemination of information. Distribution of leaflets was done which were developed specially on osteoporosis in Kannada and English languages. After a whole day of nutrition education session, the mean scores of KAP before and after were consolidated and analyzed to assess the impact of nutrition education on Knowledge, Attitude and Practice levels of subjects to infer statistically. Gain in scores and per cent improvement was calculated using following equations.

Gain in scores $=$ MS of Post-test- MS of Pre-test.

Per cent Gain $=($ Gain in scores $/$ Pre test scores $) \times 100$

Mean and standard error of mean were computed for variables. To test the significance of difference of two mean values of variable/parameter at baseline and after nutrition counselling, paired t-values were worked out using suitable statistical package (SPSS 14.0 for windows, SPSS Inc., Chicago, USA). Correlation of coefficient was assessed using the base of measurements as per guidelines described in the Report of a Joint WHO/FAO Expert Consultation, WHO (Nishida et al, 2004).

\section{RESULTS AND DISCUSSIONS}

Table 1 reveals that maximum number of female subjects $(67 \%)$ were in the sample selected as compared to male subjects (33\%). The age wise distribution of subjects depicted that higher numbers of subjects suffering from orthopedic ailments were in the age group of 40-49 years both in male and female group. Similar trend of higher prevalence of women between 40-60 years of age was observed by Sangha et al., 2006. Higher per cent of Saudi women with low BMD levels were in the mean age of 55.26 year as reported by Aljohara et al., 2014. It was notable that about 35 per cent female subjects and 20 per cent belonged to less than 30 years of age group. The data depicted in pictorial representation clearly indicates the distribution of 
Table 1. Distribution of osteoporotic subjects based on Socio economical background

\begin{tabular}{|c|c|c|c|c|c|c|c|}
\hline Factors & & \multicolumn{2}{|c|}{ Male } & \multicolumn{2}{|c|}{ Female } & \multicolumn{2}{|c|}{ Total } \\
\hline$E d u$ & Illiterates & - & - & 3 & 15 & 3 & 10 \\
\hline \multirow[t]{4}{*}{ level } & $<\mathrm{SSLC}$ & 1 & 10 & 3 & 15 & 4 & 4 \\
\hline & SSLC & 1 & 10 & 5 & 25 & 6 & 13 \\
\hline & $<$ PUC/Diploma & 1 & 10 & 9 & 45 & 16 & 20 \\
\hline & Degree Above & 7 & 70 & - & - & - & 53 \\
\hline Size of & $\leq 2$ & 1 & 10 & - & - & 1 & 4 \\
\hline \multirow[t]{3}{*}{ family } & $>2$ to 4 & 8 & 80 & 15 & 75 & 23 & 76 \\
\hline & $>4$ to 6 & 1 & 10 & 5 & 25 & 6 & 20 \\
\hline & $>6$ & - & - & - & - & - & - \\
\hline Type of & Joint & - & - & 2 & 10 & 2 & 7 \\
\hline \multirow[t]{9}{*}{ family } & Nuclear & 9 & 90 & 18 & 90 & 27 & 89 \\
\hline & Single & 1 & 10 & - & - & 1 & 4 \\
\hline & Occupation & & & & & & \\
\hline & Employed & 8 & 80 & 6 & 30 & 14 & 46 \\
\hline & Not employed & 2 & 20 & 14 & 70 & 16 & 54 \\
\hline & Type of diet & & & & & & \\
\hline & Lacto vegetarian & 5 & 50 & 5 & 25 & 10 & 33 \\
\hline & Ovo lacto veg. & 1 & 10 & 5 & 25 & 6 & 20 \\
\hline & Non vegetarian & 4 & 40 & 10 & 50 & 14 & 47 \\
\hline \multirow{4}{*}{$\begin{array}{l}\text { Monthly } \\
\text { income }\end{array}$} & 1000 to 4999 & 1 & 10 & 3 & 15 & 4 & 13 \\
\hline & 5000 to 9999 & 6 & 60 & 17 & 85 & 23 & 76 \\
\hline & 10000 to 19999 & 3 & 30 & - & - & 3 & 11 \\
\hline & $20000 \&$ Above & - & - & - & - & - & - \\
\hline
\end{tabular}

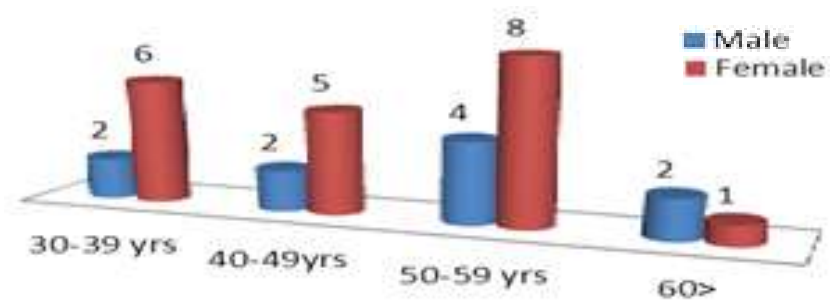

Fig. 1. Age wise distribution of subjects selected for nutrition education

subjects based on age group (Fig. 1). Maximum number of subjects $(76 \%)$ had the range of monthly income between Rs.5000-9999 followed by thirteen per cent respondents with monthly income between Rs.10004999. About eleven per cent were earning monthly income of Rs.10,000-19,000 and none have more than Rs.20,000 monthly income. As the subjects were from sub urban areas of a district in Karnataka the monthly income range was observed to be very nominal. But it was interesting to note that higher middle class as per the monthly income range (Rs.5000-19,000) has been much observed to have prevalence of symptomatic osteoporosis. In the contrary, AlQuaiz (2014) observed a similar trend of prevalence of osteoporosis among high and lower economic groups. The reason could be attributed to several other factors such as education, awareness and dietary practices.

The education level of male subjects was higher i.e. degree and above (70\%) and none were illiterates (Table 1). Among female subjects, maximum had studied up to PUC level (45\%). It was also notable that fifteen per cent female subjects were illiterates. When subjects are combined irrespective of gender, similar trend of higher prevalence of osteoporotic symptoms were observed in well-educated sample of subjects. Higher per cent of male subjects were employed $(80 \%)$ but in contrary, maximum number of female subjects (70\%) were not employed, were home makers. Maximum subjects were unemployed when combined irrespective of gender $(54 \%)$.

Distribution of subjects based on size of family revealed that higher per cent of male and female subjects ( $80 \%$ and $75 \%$ respectively) had family size of $2-4$ members. Again the results are interesting to show that $25 \%$ of female subjects had a family size of 4 to 6 members, whereas $10 \%$ of male subjects had family size of 4 to 6 members. Combined data depicted that maximum number of total selected subjects had a family size of 2 to 4 members that is almost a picture of nuclear family. This can be attributed to the data of type of the family depicted that maximum number of subjects $(90 \%)$, either male or female are having nuclear type of family (Table 1). Only ten per cent of female subjects were living in joint family system where as none of the male subjects had joint family. However, ten per cent of male subjects are single/not married. The results can be attributed to the drudgery related physical stress on female subjects residing in nuclear families and as well as for the male subjects residing single which might have affected the bone health both for physical as well as dietary factors. Nuclear family adding more stress physically or mentally than joint family system has reflected in the higher prevalence $(90 \%)$ of osteoporosis among both type of subjects.

It was observed that Ova-lacto vegetarians (20\%) had lower prevalence of osteoporotic ailments and nonvegetarians $(47 \%)$ had higher prevalence. Asomaning (2006) and Byberg et al (2015) have reported the similar data where subjects with only vegetarian base had lower BMD levels. It is evident that none of the 
Table 2. Involvement of subjects in physical and household activity

\begin{tabular}{llllllll}
\hline \multirow{2}{*}{ Activity } & & \multicolumn{2}{c}{ Male } & \multicolumn{2}{c}{ Female } & \multicolumn{2}{c}{ Total } \\
& & No. & $\%$ & No. $\%$ & No. $\%$ \\
\hline Physical & Yes & 3 & 30 & 2 & 10 & 5 & 17 \\
& No & 7 & 70 & 18 & 90 & 25 & 83
\end{tabular}

Household

$\begin{array}{lllllll}\text { Done by self } & 3 & 30 & 18 & 60 & 21 & 70\end{array}$

$\begin{array}{lllllll}\text { Done by domestic servant } & 7 & 70 & 2 & 40 & 9 & 30\end{array}$

Table 3. Prevalence of family medical history among subjects

\begin{tabular}{lccc}
\hline Medical history & Male & Female & Total \\
\hline Fractures & 1 & 6 & 7 \\
Liver disorders & - & 1 & 1 \\
Hypertension & 5 & 15 & 20 \\
Diabetes Mellitus & 2 & 8 & 10 \\
Coronary heart disease & - & 1 & 1 \\
\hline
\end{tabular}

* Total don't tally due to multiple answers

Table.4. Classification of subjects based on Body Mass Index

\begin{tabular}{|c|c|c|c|c|c|c|c|}
\hline \multirow{2}{*}{ BMI } & & \multicolumn{2}{|c|}{ Male } & \multicolumn{2}{|c|}{ Female } & \multicolumn{2}{|c|}{ Total } \\
\hline & & $\mathrm{N}$ & $\%$ & No. & $\%$ & No. & $\%$ \\
\hline Underweight & $<18.5$ & 0 & 0 & 0 & 0 & 0 & 0 \\
\hline Normal & $\geq 18.5-24.9$ & 2 & 20 & 4 & 20 & 6 & 19.8 \\
\hline Overweight & $25.0-29.9$ & 5 & 50 & 9 & 45 & 14 & 47 \\
\hline Obese grade 1 & $30.0-34.9$ & 2 & 20 & 1 & 5 & 3 & 9.9 \\
\hline Obese grade 2 & $35.0-39.9$ & 0 & 0 & 6 & 30 & 6 & 19.8 \\
\hline Obese grade 3 & $\geq 40$ & 1 & 10 & 0 & 0 & 1 & 3.5 \\
\hline Total & & 10 & 100 & 20 & 100 & 30 & 100 \\
\hline
\end{tabular}

Source: Report of a Joint WHO/FAO expert consultation, WHO (Nishida et al., 2004)

subjects were vegans. Hypertension was the common family medical history reported by maximum numbers of subjects followed by Diabetes Mellitus and fractures (Table 2). Involvement in physical activities or exercises was not much observed by maximum number of subjects. Assistance of maid servants was observed to be taken by most of the subjects to carry out house hold activities. Aljohara (2014) measured the factors associated with low BMD in Saudi women in Riyadh, Saudi Arabia and reported that physical inactivity increased by more than two-fold among men in Saudi Arabia within the last two decades whereas it has long been the predominant lifestyle among Saudi women.

Frequency of food consumption revealed that Rice was daily consumed but ragi was consumed on weekly basis by maximum member of subjects. Few leafy vegetables and other vegetables were consumed regularly. Though the consumption of leafy vegetables was found to be satisfactory as per frequency consumed the bioavailability of calcium might be the reason for prevalence of symptomatic osteoporosis. Ground nuts and Niger seeds were common oil seeds consumed regularly. Roots and tubers, onion and garlic consumed by all the subjects on daily basis. Banana was consumed daily by all the subjects, whereas apple, orange, sapota and guava were consumed frequently by only 16.5 33.0 per cent of subjects. None of the subjects consume milk and milk products on daily basis, but was observed on weekly or monthly basis by 66.5 per cent of subjects which might be one of the reasons for prevalence of osteoporotic symptoms. Egg and chicken consumption was more frequent than other meat.

Maximum number of (40-90\%) subjects (both male and female) informed that they are not much involved in physical activity or any physical exercise. It was supported by the findings of Table 3 that only 10 per cent male and 60 per cent female subjects are doing household activities on their own. About 70 per cent of male subjects and 40 per cent of female subjects do the house hold activities with the assistance of domestic servant. Javed et al (2015) observed similar trend of sedentary life style and lack of awareness about the importance of exercise in relation to bone health among the majority of the college teachers at Lahore who had osteoporosis conditions (BMD ratio in between -2.58 to -4.0 ).

Table 4 indicated that Overweight and obesityGrade I was prominent among all the subjects whereas Grade II and Grade III obesity was also observed. It was notable that 19.8 per cent subjects were in normal BMI range. Maximum subjects were overweight having BMI range $\geq 25$ to 29.9 . Grade 1 obesity was more prevalent among males $(20 \%)$ than females $(5 \%)$ whereas grade 2 obesity was prominent among females $(30 \%)$. Male subjects were more osteoporotic whereas osteopenia was highly prevalent among females as per their bone minerals density (BMD) reports (Fig 2). It was reported by several survey research that BMI was found to be significantly associated with low BMD at both sites in premenopausal women, while the association was lost in postmenopausal females (Jameela banu,2013 and Kumar et al., 2016)

Table 5 depicts that osteoporotic condition has 


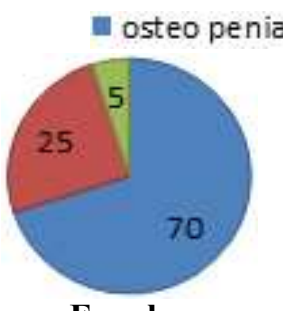

Female

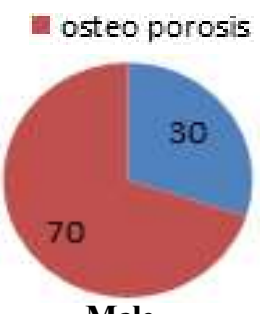

Male

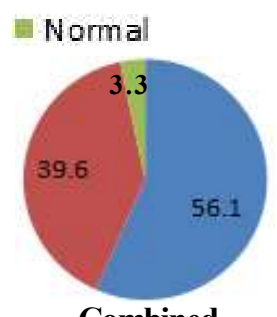

Combined
Fig. 2. Per cent distribution of subjects in different osteoporotic conditions based on BMD values

Table 5. Association of osteoporotic condition with gender, age and BMI of subjects

\begin{tabular}{lcccccc}
\hline & Gender & Age & Height & Weight & BMI & OC \\
\hline Gender & 1 & & & & & \\
Age & -.170 & 1 & & & & \\
Height & $-.426^{*}$ & .244 & 1 & & & \\
Weight & $-.573^{* *}$ & .202 & $.376^{*}$ & 1 & & \\
BMI & -.100 & -.088 & $-.565^{* *}$ & $.541^{* *}$ & 1 & \\
OC & $-.431^{*}$ & $.428^{*}$ & .088 & .284 & .160 & 1 \\
\hline
\end{tabular}

$\mathrm{OC}=$ Osteoporotic Condition; Base for measurement $:$ Nishida et al. (2004). Report of a Joint WHO/FAO Expert Consultation, WHO,

positive correlation with age, height, weight and BMI. It can be attributed to the higher per cent of osteoporotic subjects having higher BMI. Asomaning (2006) studied the association of osteoporosis and BMI and observed that women with low BMI are at increased risk of osteoporosis in a a cross-sectional study among women aged 50-84 years in the United States. In a recent study, Aljohara (2014) measured the prevalence and factors associated with low BMD in Saudi women in Riyadh, Saudi Arabia and found that there is a positive association of age, education and dietary products with low levels of BMD i.e. osteoporotic conditions. It was observed that physical inactivity increased by more than two-fold among men in Saudi Arabia within the last two decades whereas it has long been the predominant lifestyle among Saudi women. In the present study also a positive association is found with age, height, weight, and BMI.

Impact of nutrition education on mean scores of $K A P$ subjects : The impact of nutrition education was evident by increased scores of knowledges, attitude and practice of subjects (Fig.5). The mean scores of knowledge increased to 3.30 from 2.22 for male subjects and enhanced to 3.37 from 2.55 for female subjects. Per cent gain of knowledge was higher among male subjects $(54.8 \%)$ compared to female subjects $(36.9 \%)$. The mean scores of attitude had increased from 3.10 to 3.85 among male and from 2.86 to 3.55 among female subjects. The per cent gain of attitude for both the subject was at a range of 35.6 to $36.5 \%$. The mean scores of practice enhanced from 3.45 to 4.05 for male subjects and similarly from 3.62 to 4.12 among female subjects. The per cent gain in practice scores was slightly higher among male subjects (19.3\%) compared to female subjects $(15.0 \%)$.

The overall percentage gain of knowledge, attitude and practice for all subjects when combined was 42.9 per cent, 37.4 per cent and 15.4 per cent respectively which was statically significant at 5 per cent level indicating the positive impact of nutrition education on KAP levels. This clearly showed that the impact of nutrition education was more for knowledge and practice levels of male subjects. The increase in the attitude scores was in the similar line for both the subjects indicating modification in attitude was similar for all subjects irrespective of gender as a result of nutrition education. This has been clearly depicted in graphical representation in fig. 3, fig. 4 and fig. 5 respectively. Combined values of all subjects have shown a per cent

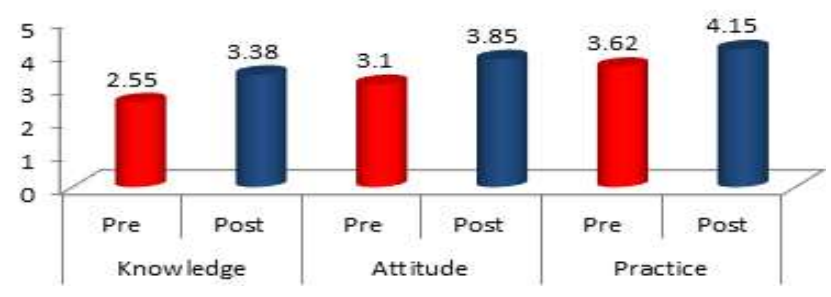

Fig. 3 . Impact of nutrition education on mean scores of KAP of female osteoporotic subjects

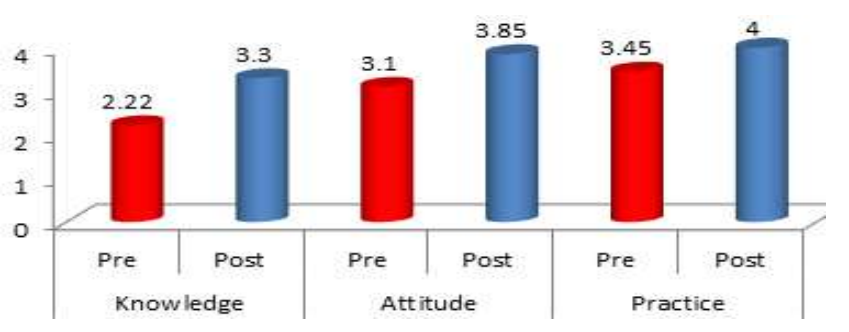

Fig. 4. Impact of nutrition education on mean scores of KAP of male osteoporotic subjects

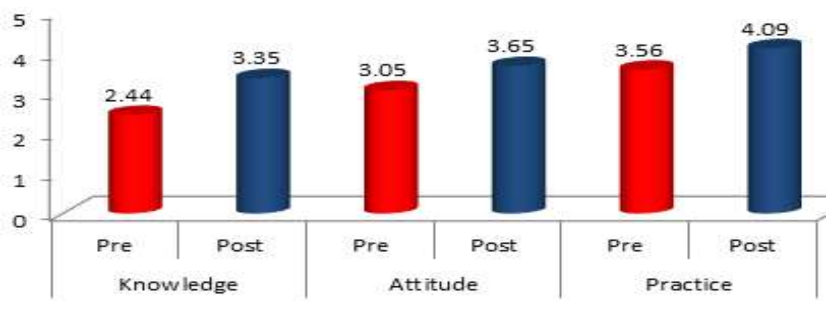

Fig. 5. Impact of nutrition education on mean scores of KAP of osteoporotic subjects 
gain of knowledge, attitude and practice as 42.9 per cent, 37.4 per cent and 15.4 per cent respectively. Kaur and Sangha (2007) observed positive impact of nutrition education on the intake of dietary antioxidants and also on nutrition knowledge. The total cholesterol level of the subjects was found to be decreased by 9.27 per cent after the nutrition education (from $215 \pm 36.5$ to $195.06 \pm 31.62 \mathrm{mg} \%$ ). The mean diet scores significantly improved from $1.12 \pm 0.86$ to $2.25 \pm 1.13$ after nutrition education with gain of 1.13 scores. The quantum of improvement was 2.01 times. Choudhury et al (2008) studied the impact of visual media on knowledge, attitude and practice of high school children $(n=120)$ of Hisar district of Haryana state that education with visual media was effective and enhanced the knowledge and brought out attitudinal change. They suggested for repeated exposure through media and personal contacts to bring significant improvement in the attitude and practice through nutrition education.

The overall total scores of knowledges, attitude and practice indicated a higher per cent gain among female subjects (16.4\%) compared to male subjects (14.7\%). The per cent gain of overall Knowledge, attitude and practice scores for all the subjects was 10.75 per cent. All the mean per cent gain values were significant at 5 per cent level indicating the effectiveness of nutrition education along with $\mathrm{AV}$ aids. The gain is satisfactory for one session of counselling. This clearly shows that nutrition counseling along with pharmaceutical therapy has more impact on remedial interventions to bring positive modification in knowledge, attitude and practice of dietary pattern as well as lifestyle which has consequential benefits to manage the health conditions. Similar observations were reported by Choudhary (2008) that impact of a package of media including posters, charts, leaflets and booklet was evident with significant gain in knowledge and change in attitude by nutrition education for schoolchildren in Hisar.

\section{CONCLUSION}

The study indicated that male and female subjects of middle age group i.e. $40-49$ years were suffering more from osteoporotic subjects. Irrespective of gender, higher prevalence of osteoporotic symptoms was observed among subjects of higher middle class and well-educated families. Physical non activity was more prevalent among subjects. Higher prevalence of osteoporosis was among the subjects of nuclear type of family (With average 2-4 members in family). Ova lacto vegetarians had lower prevalence of osteoporosis than non-vegetarians. Frequency of food consumption was meager for ragi, milk and milk products, meat and meat products and other vegetables. The positive impact of nutrition education was evident by the significant increase in mean scores of knowledge.

It can be recommended that nutrition counseling unit has to be established for every orthopedic medical center/ nursing homes to bring holistic approach to modify the knowledge levels of patients towards dietary and lifestyle management which can improve their attitude and consequentially modify the health and nutritional practices. Mass media exposure and audiovisual education materials are beneficial for effective nutrition counseling. Hence development and use of nutrition counseling material in health supporting system is effective for nutrition education.

\section{CONFLICTS OF INTEREST}

The authors declare that they have no conflicts of interest.

\section{REFERENCES}

AlJohara, M.; AlQuaiz, Ambreen Kazi; Salwa, Tayel; Shaffi, Ahamed Shaikh; Abdullah, Al-Sharif; Saleh. Othman; Fawzia, Habib; Mona, Fouda; Riad, Sulaimani (2014). Prevalence and factors associated with low bone mineral density in Saudi women: a community based survey BMC Musculoskelet Disord. [Online] 15 (5) pp10. available on https:// ecommons.aku.edu/pakistan_fhs_mc_chs_chs/726/

AlQuaiz., A.M.; Siddiqui, A.R.; Qureshi, R.H.; Fouda, M.A.; AlMuneef, M.A. and Habib, F.A, (2014). Women health in Saudi Arabia: a review of non-communicable diseases and their risk factors. Pakistan J Medical Sci., 30 (2) : 422.

Asomaning, K.; Bertone-Johnson, E.R.; Nasca, P.C.; Hooven, F.; Pekow, P.S. (2006). The association between body mass index and osteoporosis in patients referred for a bone mineral density examination. J. Womens Health (Larchmt).15 (9) :1028-34.

Byberg, L.; Bellavia, A.; Orsini, N.; Wolk, A.; Michaëlsson, K. (2015). Fruit and vegetable intake and risk of hip fracture: a cohort study of Swedish men and women. J. Bone Miner Res., 30 (6) : 976-84 
Choudhary, S.; Kaushik, S. and Asrani, S. (2008). Impact of visual media on knowledge, attitude and practice of school children regarding nutrition education. J. Dairying, Foods and Home Sci., 27 (1) : 75-78.

Jameela, Banu (2013). Causes, consequences, and treatment of osteoporosis in men. Drug Des Devel Ther. 22 (7) : 849-860.

Javed, Z.; Imam, S.F.; Imam, N.; Saba, K.; Bukhari, M.H. (2015). Bone mineral density and diet of teachers of College of Home Economics at Lahore. Pakistan J Medical Sci., 31 (4) : 970-74. doi: 10.12669/pjms.314.8433.

Kaur, J. and Sangha, J. (2007). Hypolipidemic effect of dietary antioxidants and impact of nutrition counseling on the nutrition knowledge scores of at-risk coronary heart disease subjects. J. Dairying, Foods \& H.Sci. 26 (2) : : 106-113.

Kumar, A.; Sharma, A.K.; Mittal, S.; Kumar, G. (2016). The relationship between body mass index and bone mineral density in premenopausal and postmenopausal North Indian women. J. Obstet Gynaecol India. 66 (1) : 52-56. from: http:// www.cdc.gov/nchs/data/nhanes/nhanes_03_04/BM.pdf. Accessed October 28, 2014.

Sangha, J.; Pandher, A.K. and Kaur, N. (2006). Impact of nutrition education on nutrition knowledge of the parents of obese children. The Indian J.Nutri.Diet., 42 (1) : 208-211.

World Health Organization. (1994). Assessment of fracture risk and its application to screening for postmenopausal osteoporosis : report of a WHO study group (meeting held in Rome from 22 to 25 June 1992). Organ Tech. Rep. Series, 843 : 1129. World Health Organization. https://apps.who.int/iris/handle/10665/39142

Nishida, C.; Ricardo, U.; Shiriki, K. and Shetty, P. (2004). The joint WHO/FAO expert consultation on diet, nutrition and the prevention of chronic diseases: process, product and policy implications Public Health Nutri., 7 (1A) : 245-250 